[200] Delinquency and mental defect (III.).-F. C. Shrubsall. Brit. Jour. Med. Psychol., 1923, iii, 179.

IN $1922,1.3$ per cent. of the school-age population of London was mentally defective. Delinquents show a slightly greater average intelligence than the mass of day special school children in the mental defective schools. In adults the average mental age of defectives is $\mathbf{7 \cdot 9}$, and of defective delinquents, 8.5. In a percentage frequency of different offences, wandering provided the maximum number of cases, showing a low grade of mentality. Shrubsall agrees with East's observation that women charged with soliciting show a relatively high mental age for defectives. As for men, stealing is more frequently found among the unemployable classes, while, in women, the largest figure is for those in regular work. The author thinks that Burt's definition of 'temperamental defectives' rather than moral imbeciles would only include those with the unstable emotional temperament. In the true moral imbecile the defect is not so much lack of inhibition as lack of feeling, the emotions being too neutral.

Robert M. Riggall.

[201] Delinquency and mental defect (IV.).-W. H. B. Stoddart. Brit. Jour. Med. Psychol., 1923, iii, 188.

Delinquency refers to the tendency to commit crimes and not to the misdeeds themselves. Morality is simply the control of instincts, and is responsible for the Freudian conception of repression. Idiots and low-grade imbeciles have less control of their instincts and are more immoral in the widest sense than normal children. On the other hand, the moral tone of high-grade imbeciles and backward children is equal to or even in advance of normal children of their own intellectual mentality. This is a strong argument against the existence of ' moral imbecility,' which means innate delinquency with little or no intellectual defect. In progressive degeneration of the nervous system the control of the instincts is lost in the reverse order of its evolution, the last control to come being the first to go. Stoddart considers that the usual misdeeds of the child have an unconscious sexual meaning. The objects stolen or destroyed have a phallic or womb symbolism. In the author's experience the thefts are invariably related to the castration complex. Destructiveness symbolizes sadistic attacks on the mother. Delinquency may be a psychoneurosis occurring in an intellectually normal child, curable by psychoanalysis. In Stoddart's experience, psychoneuroses are chiefly found among the educated intellectual classes.

Robert M. Riggall.

\title{
PSYCHOPATHOLOGY.
}

[202] Literature and the psychopathic.-N. A. Crawford. Psychoanalytic Review, 1923, x, 440 .

The author states that two reasons explain the continued interest and charm of legend; it follows taboo and it practically always includes magic. The human race, especially the female members, cling to magical explanations, 
whil s scientific advance has scarcely touched them. Popular literature of the present day acts in a similar way, upholding taboo and, like magic, mistaking an ideal connection for a real one.

As a rule, popular fiction appeals to the adult and legend to the child, because the latter is the more primitive. The large sale of books of etiquette shows the reliance of the popular mind on established beliefs. The parallel is drawn between the public with a taste for popular literature and the psychopathic patient. Both are upholders of taboo and both believe in magic. The psychopathic does not realize the purpose of his psychopathy nor the fiction devotee the mental state that enables him to enjoy such literature.

Modern realistic literature clearly reveals the meaning of common artistic symbols as they are found in dream life, literature and legend. It also shows that the customary repressed life is frequently psychopathic and does not lead to happiness and freedom. Sexual understanding is sure to come into conflict with popular beliefs, fears and taboos, because these latter are, for the most part, based on error. This type of literature is rejected as immoral for the above reason.

Art is all creative ; it is a form of sublimation, and the reader of a novel must follow the writer in this act of sublimation. This the psychopathic and the public have an aversion to do. They do not desire to have their illusions dispelled. This may also account for the common man's objection to the arts.

Davil) Matthew.

[203] The nature of autosuggestion.--Ersest Jones. Brit. Jour. Med. Psychol., 1923, iii, 194.

Dr. Joves opens his paper with an attempt to come to some understanding as to what are the essential characteristics of suggestion in general. He shows that three processes are involved : (1) emotional rapport, (2) concentration upon a given idea with inhibition of contrary ideas, (3) free development of the suggested idea. Now two schools have sprung up, depending upon a difference of opinion as to the way in which rapport operates. The oneheterosuggestionist-lays stress upon the part played by the operator; the other-autosuggestionist-considers the essential thing to be the attitude of the subject. In practice, however, it is by no means easy to draw a sharp distinction between the two; indeed, their relationship is so intimate as to render it probable that the operative agents are merely variants, not distinct forces. The one point of difference is in respect of the idea upon which concentration takes place. With heterosuggestion the idea is the father-imago, with autosuggestion the idea is the actual : elf. Dr. Jones here discovers the nodal point connecting the two; both are reanimations of narcissism, but heterosuggestion proceeds via a hypercathexis of the father-imago and the ego-ideal, while autosuggestion reaches back to the primary undifferentiated narcissism of the infant. Thus, the question whether most heterosuggestion is

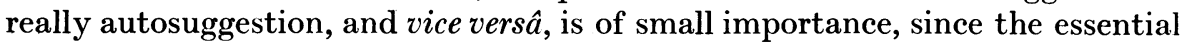
agent in both is narcissism, and the difference consists only in the method by 
which this is activated. It would appear that, practically, it is easier to mobilise narcissism by means of heterosuggestion than directly by autosuggestion, and that the former is generally a phase passed through in the attainment of the latter. Successful autosuggestion presupposes harmony between the narcissism of the ego-ideal and that which has remained attached to the real ego. The difficulty in most cases, however, is precisely a lack of harmony between the two. Finally, Dr. Jones considers the therapeutic significance of the thesis he advances. All possible means of dealing therapeutically with the neurotic situation are reducible to two only. Either the libidinal energy of the impulse can by suggestion be reconverted into the narcissism whence it proceeded, or else the assimilative capacity of the egoideal can be raised and the patient's narcissism be diverted into more developed forms of mental activity ; the latter is the aim in psychoanalytical treatment. These alternatives are mutually contradictory, and it is, therefore, fundamentally imposisible to combine them.

Alfred Carver.

[204] From psychoanalysis to psychosynthesis.-PALL BJERre. Psychoanalytic Reriew, 1923, x, 361.

Mextal disintegration is the outstanding feature and symbolization the individual mark of mental disorder. Therefore psychosynthesis is the logical cure. Psychoanalysis is the necessary forerunner of psychosynthesis. Psychoanalysis fails because of the process of petrifaction or mechanization of the symptoms, i.e., after the obsession or other symptom has been analysed into its elements of childhood impressions, it still continues to whirl relentlessly in the brain.

Neurasthenia, hysteria, lunacy and dementia are forms of spiritual death. Spiritual healing requires a universally human and philosophical substructure if it is not to remain suspended in the air. This appears to be what the author means by psychosynthesis.

The healing power of nature is remarked upon in the psychical as well as the physical spheres. During sleep, as a rule, a psychosynthesis actually is brought about which involves a spontaneous healing. The part psychoanalysis has played in enabling us to interpret dreams is recognized, but the wish theory of dreams is rejected. In its place the author presents the theory that dream-formation, like the creation of the artist, is a process of psychosynthesis in the proper sense-a dissolution of contrasts into a new vital factor. This factor is the creation resulting from inspiration. Symbolformation is defined as the conversion of allness into oneness. It is the healing power of nature in the psychical sense.

The presumed failure of psychoanalysis is held to be due to the failure to appreciate the dynamic aspect of symbol-formation.

Two examples of the author's symbol-interpretation are given : $\mathbf{A}$ fear of heights symbolizes a desire to rise in the world. A dream in which a married woman discovers that a stone has fallen from her ring is interpreted as follows : The stone represents the troubles of the patient, e.g., matrimonial dread, etc. The ring is the symbol of marital fidelity and the high stardard of life set by 
its previous owners. The dream symbolizes the patient's relief from her troubles-her cure. The weight has fallen out. This healing is produced by intellectual clarification.

After reading this article we are not surprised that the author finds it necessary to supplement his analysis. He does not appear, whatever his technique, to carry the analysis far enough to disclose the fundamental conflicts.

\section{[205] Psychoanalysis and pedagogy.} Psychanalysis, 1923, i, 364.

David Matthew.

A. Maeder. Jour. of Sexology and

IT has been established that two powerful spheres of influence are involved : the influence of the teacher's unconscious on the pupil, and that of the pupil's unconscious on the teacher. In judging a child's talents there are two factors to be considered : a static factor (disposition) and a functional factor. Only by a laborious conquest of the negative transference by means of psychoanalytic treatment, in an example quoted, was it possible to bring out the utilization of a boy's natural gifts in behalf of the neglected subjects. This negative complex has not only a great individual significance, but also a social significance, inasmuch as it tends to infect or intensify the negative complex of other pupils. The pupil studies the teacher from all angles and soon finds his weak spots; he takes advantage of these to triumph over the person in authority, especially if the youngster has a negative father-complex. One's complexes make one blind. This applies to the teacher also. The teacher, whog is himself equipped with a strong negative complex, cultivates that complex in his pupils. A teacher should be free from psychic dissociations. There is a natural ' urge' in the child for guidance, and this normal positive fathertransference should be utilized by the educator as a power. The teacher must be acquainted with these natural forces and know how to guide them properly. We are really complying with an inner requirement when we give the child proper guidance. At present, psychoanalysis seems to offer basic data towards the solution of two important questions in pedagogy. The psychoanalytic viewpoint gives us the explanation for the true relations between teacher and child, and it also reveals to us an important aspect of the psychic evolution of the child and its natural requirements-knowledge which gives us guiding lines for the science of education.

C. S. R.

[206] Stuttering and anal eroticism.-S. A. Tannenbaum. Jour. of Sexology and Psychanalysis, 1923, i, 419.

THE author states that experience proves that in actual practice stuttering is no more easily curable now than it was in the past, and that in this it does not differ from other severe psychoneuroses. He gives excerpts from the opinions of $\mathbf{R}$. Brun, who recently reported on the analysis of two cases of severe habitual stuttering and who regarded the condition as a peculiar form of compulsion-hysteria. These youths of eighteen and twenty, respectively, both traced their neurosis back to their fourth year of life. Brun states that 
they both manifested a high degree of anal eroticism in early childhood, that direct anal erotic activities were repressed; in its place there appeared a strikingly strong tendency to coprolalia as a substitute-gratification. This, too, was in turn subjected to repression which, however, only succeeded incompletely, i.e., there now ensued the neurotic symptom-formation, viz., stuttering, which proved to be a typical compromise between two impulses. This analyst further stated that in both cases the symptom completely disappeared after the unveiling and disposal of the infantile analerotic and coprolalic experiences and phantasies. Tannenbaum considers all these points, differs entirely from the conclusions drawn, and regards the analysis as having neither scientific nor practical value.

C. S. R.

[207] Condensation and resymbolization in dream interpretation.-GEoRgE Stragnell. Psychoanalytic Review, 1893, x, 431.

THIs is a fairly orthodox interpretation of a dream, and is of special interest because of the author's endeavour to facilitate the explanation by a series of diagrams composed of circles and lines. The value of these diagrams must be left to the reader's own judgment.

D. M.

[208] Transference and sex.-L. D. Hcbbard. Psychoanalytic Revierv, 1923, $\mathrm{x}, 453$.

THE author summarizes the article as follows :

The sex of the analyst is an important factor in determining the nature of the transference, upon which depends the success of the analysis.

Those patients having a pronounced homosexual trend make good transfers to analysts of the same sex.

Patients showing marked heterosexual trends do best with analysts of the opposite sex, provided the transfer is tactfully handled and not allowed to become erotic.

The dominating trend may be determined in most cases by a careful study of the history.

A change of sexual trend in the course of the analysis is not often a source of danger, because it is usually a modification of the original balance, though in some cases it may be a marked change indicating recovery.

David Matthew. 